"New policy designs will need to have an explicit dual purpose, combining the objectives of labor migration and humanitarian protection."

\title{
Can Labor Immigration Work for Refugees?
}

\author{
MARTIN RUHS
}

$\mathrm{M}$ ost high-income countries make a strict distinction in their immigration policies between refugees and those deemed to be labor migrants. While refugees are typically admitted on humanitarian grounds-albeit with debates in many countries about who qualifies and what degree of protection they are entitled to receive-labor migrants are usually admitted with the explicit aim of benefiting the economy and society. The Global Compact on Refugees, a new nonbinding United Nations framework for improved global governance and more equitable sharing of responsibility, recommends that highincome countries take in some refugees as labor migrants. Is this a good idea? Could it work?

How to help the rapidly growing number of refugees in the world is among the greatest moral and political challenges of our time. According to the UN High Commissioner for Refugees (UNHCR), there are now over 25 million recognized refugees, the highest number on record. The vast majority, about 85 percent, have taken refuge in relatively low-income countries. The top 10 hosts in 2017 included four of the world's least developed countries-Uganda, Sudan, Ethiopia, and Bangladeshand five middle-income countries: Pakistan, Lebanon, Iran, Jordan, and Turkey (the world's leading host, with 3.5 million refugees).

Only one high-income country-Germany, hosting one million refugees-made the top 10 . When refugees are considered as a share of the domestic population, Sweden is the only high-income country among the top 10 hosting nations, with 24 refugees per 1,000 people, compared with 43 per 1,000 in Turkey, 71 per 1,000 in Jordan, and 164 per 1,000 in Lebanon.

MARTIN RUHS is the deputy director of the Migration Policy Center at the European University Institute and an academic co-director of the Mercator Dialogue on Asylum and Migration (MEDAM).
Why is the global distribution of refugees so heavily skewed toward lower-income countries? The first reason is straightforward: the great majority of the world's refugees came from low-income countries and fled to neighboring or other nearby low- or middle-income countries. As of 2017, over two-thirds of refugees originated from just five low-income countries-Syria, Afghanistan, South Sudan, Myanmar, and Somalia-and most have found "safe havens" in nearby countries.

The second reason has to do with the politics of immigration in rich countries: most do not offer opportunities for people to travel legally to their territories in order to apply for asylum. Forced migrants who wish to apply for asylum in highincome countries must do so by engaging in irregular migration-defined here as the unauthorized crossing of national borders-which often involves long and dangerous journeys across land and sea. Many rich countries have stepped up their efforts to reduce illegal border crossings over the past few decades, especially since the large increases in the numbers of Syrian and other migrants arriving in Europe and claiming asylum in 2015 and 2016. With few exceptions, most rich countries also have long been reluctant to offer resettlement for large numbers of recognized refugees who have found protection in "first countries of asylum" in or near conflict regions.

The United States has traditionally been the country that accepts by far the largest number of resettled refugees-those whose status has been determined by UNHCR and are transferred from a country of first asylum to another country that has agreed to admit them and ultimately grant them permission to stay permanently. However, the US intake has dropped significantly of late. The Trump administration announced in late 2017 that it would reduce the annual cap on resettlement to 45,000 per year, less than half the 110,000 cap set during the final year of the Obama admin- 
istration. (In September 2018, the Trump administration announced a further reduction in the cap, to 30,000 - the lowest since the program began in 1980.)

Several other high-income countries have also reduced their resettlement numbers in recent years; some, such as Austria and Denmark, have suspended resettlement altogether. In 2017, only 102,800 refugees were resettled worldwide, a reduction of nearly 50 percent from 2016, and equivalent to only about 0.5 percent of the global refugee population.

\section{NARROW PATHS}

The highly unequal distribution of refugees across the world and the shrinking of the already limited legal pathways to protection in rich countries have led to calls for alternatives. One idea that has been around for a while, and has gained prominence in recent years, is to encourage highincome countries to use labor immigration policies to admit refugees.

The Global Compact on Refugees recommends "complementary pathways" to resettlement such as "labor mobility" opportunities for refugees. This is meant to contribute to the compact's overall aims, which include enhancing refugees' self-reliance, easing the pressures on host countries in low-income regions, and promoting conditions in countries of origin that will allow for the safe return of refugees.

Most labor migrants in high-income countries enter through programs that grant temporary residence status on arrival, though some allow an eventual transition to permanent status. Most of the programs target migrants with particular skills, and treat higher- and lower-skilled workers differently. Programs for higher-skilled migrant workers generally place fewer restrictions on admission and grant migrants more rights, especially for welfare, residency, and family reunion, than programs targeting lower-skilled migrants.

The most common policy tools employed to regulate the admission of labor migrants in highincome countries include quotas and the requirement of a job offer before admission. Temporary labor migration programs typically limit workpermit holders' employment to specific occupations or sectors, and require migrants to prove that they will not rely on public assistance to support themselves or their families. They also usually require employers to advertise vacancies in the domestic labor market for a minimum period before they can apply for a work permit to use to recruit a migrant worker.

Debates on labor immigration among the public and policy makers vary across countries but proposals for dealing with the issue are typically framed in highly consequentialist terms. In other words, they are based on the perceived or real costs and benefits of particular admission policies for the existing residents of the host country, without significant consideration of the interests of new migrants or their countries of origin. Humanitarian considerations typically play no role in the labor immigration policies of high-income countries.

Realistically, that means an alternative labor migration pathway for refugees cannot be designed purely on humanitarian grounds. This would essentially amount to expanding humanitarian resettlement, which many high-income countries are reluctant to do. The key question then is whether an alternative pathway for refugees should be based on labor immigration policy objectives alone, which would subject refugees to the same criteria used for regulating the admission of migrant workers, or whether a new approach should have a humanitarian element.

In my view, policies that explicitly include a mix of both labor immigration and humanitarian objectives will have the best chance of winning approval and benefiting the largest number of refugees. For one thing, if refugees are admitted under the umbrella of a labor immigration program and there is an explicit recognition that the policy includes a humanitarian component, it should be easier to justify exemptions from some admission requirements that apply to other labor migrants.

Treating refugees purely as labor migrants without any recognition of their special status will not benefit many for the simple reason that refugees would need to compete for admission with other migrants from all around the world. So a more effective approach would be to design a program that is based, as much as possible, on the key features of labor immigration policies but also includes special measures for refugees.

Such a mixed policy would be similar, in terms of combining different objectives, to seasonal mi- 
grant worker programs introduced in New Zealand in 2007 and in Australia the next year for migrants from islands in the South Pacific. These policies have an explicit dual objective: to help fill labor shortages in the host countries while promoting development in the migrants' countries of origin. Of course, any mixed-objectives policy would still require a determination of exactly how much preference to give to refugees over other migrants, an especially thorny question if the overall number to be admitted is limited.

In principle, there are three broad policy approaches for using labor immigration pathways to admit refugees to high-income countries. One aims to help refugees gain access to existing labor immigration programs without making any policy adjustments for "refugee-workers." Another aims to create incentives for employers to recruit refugee-workers within the broad parameters of existing labor immigration policies. A third approach seeks to establish new labor immigration programs exclusively for refugee-workers.

\section{CleARING HURDLES}

Although bilateral migration deals are increasingly common, most labor immigration programs enacted by high-income countries apply to migrants from any country. Employers are already able to recruit refugee-workers through these existing programs. In practice, they will only do so if refugees are the most skilled and suitable candidates for the job. Factors that weigh on this judgment, along with candidates' skills and work experience, include the costs associated with recruitment and any training that may be necessary. Under almost all such programs it is the employer rather than the migrant worker who applies for the work permit, so considering employers' needs is of central importance.

Refugee-workers will be competing with migrant workers from around the world. In this competition, refugees who have escaped conflicts will be at a distinct disadvantage. They will lack information about the labor immigration programs of high-income countries, and employers and recruitment agencies are unlikely to be informed about potential refugee-workers. Various types of information portals accessible to both refugees and employers that could help match employer demands with refugee skills would help bridge that knowledge gap.

Requirements for papers such as travel documents, proof of identity, and skills certifications present a second set of hurdles for refugees. Forced migrants who have escaped from conflict zones are much less likely to have the necessary paperwork. Specific policies would be needed to lower these barriers. Relevant international organizations could be asked to help. For example, UNHCR could assist with documenting the identity of refugees; another suitable organization could be asked to find ways to certify their skills and experience.

The costs of migration, including visa fees, present yet another challenge for refugees. For many (but not all) displaced people, the costs of legal migration may be prohibitive, yet they are still lower than the costs and risks associated with paying smugglers to guide them through illegal border crossings. There may be a number of ways to lower the costs of legal entry. High-income countries could waive or reduce visa fees; nongovernmental organizations could help migrants defray travel costs.

Even if some of these hurdles could be eliminated, employers may still prefer to recruit migrant workers rather than refugees. The small numbers of refugees who would benefit are likely to be the most highly skilled and those with the most financial resources, since the current labor immigration policies of high-income countries are much more open to admitting higher-skilled migrants.

\section{EMPLOYER INCENTIVES}

A second policy option is to go beyond the provision of better information and links between employers and refugees by taking measures that are explicitly aimed at generating employer demand for refugee-workers, within the broad parameters of existing labor immigration policies. Such policies could be modified to encourage the recruitment of refugee-workers in addition to migrant workers, which could increase the total intake of migrants. Or more refugee-workers could be admitted in lieu of some migrant workers, keeping overall numbers flat. If annual quotas are used to regulate labor immigration, a limited number of places could be reserved for refugee-workers within an existing quota-an option that might find favor with politicians wary of any plan that would increase overall migrant numbers.

Where an increase in the quota would be considered undesirable or where quotas are not used, other relatively small adjustments could give employers incentives to recruit refugee-workers within the broad framework of existing policies. But some rules would be hard to change, particu- 
larly those, like job-offer requirements and occupational restrictions, at the core of a demand-led immigration policy intended to admit migrants for specific jobs or occupations. In European Union countries, many vacancies for low-skilled jobs, which otherwise might be available for refugeeworkers, are instead filled by migrants from other EU member countries who have the right to unrestricted labor mobility within the union.

The labor-market test requirement, whereby employers must advertise a job locally before recruiting a migrant to fill it, is an example of a demandside restriction that could be relaxed to encourage employer demand for refugee-workers. It has not been particularly effective at protecting domestic workers' employment prospects anyway; it merely delays recruitment of migrants. One option would be to waive the requirement for refugees. A second would be to reduce the mandatory advertising period. Either change would give employers faster access to refugee-workers.

Another measure that might have a similar effect would be to lower the administrative fees employers must pay when applying for a work permit for a migrant worker. In many countries these fees are considerable, making them one of the factors that discourage employers from recruiting migrants.

Some economists have suggested that allowing employers to pay refugees who are already in highincome countries less than the minimum wage would help facilitate the integration of refugees into the local economy. An equivalent policy applied to a labor immigration program would allow employers to hire refugee-workers on employment contracts offering less than the minimum wage, or less than the "prevailing wage" mandated by many existing programs. Alternatively, the social insurance contributions required of employers could be lowered for those hiring refugee-workers.

Reducing employment costs for refugee-workers would undoubtedly increase employer demand for such workers, but it could also undercut domestic workers who might be replaced with cheaper refugees. That would pose the danger of undermining political support for the policy in the host country. So I oppose using lower employment costs as a way of encouraging employers to hire refugee-workers. Instead, refugee-workers could be given the same (or at least similar) labor and welfare rights as those given to other migrant workers admitted under existing labor immigration policies, with the possible exception of claiming asylum.

Overall, this second policy option would likely result in larger numbers of refugees being admitted as workers to high-income countries. Its feasibility would depend on public acceptance of the humanitarian dimensions of the policy, to justify and maintain support for the relaxation of some restrictions specifically for refugee-workers. Policy makers would need to highlight the positive economic contribution that refugees can make to the host country, while emphasizing the special regulatory requirements of this type of "mixed motives migration." Realistically, under any of the policies outlined above, the number of refugee-workers would need to be capped in order to address likely concerns about uncontrolled immigration of refugees allowed to enter under laxer regulations than those applied to other migrant workers.

\section{TEMPORARY SOLUTIONS}

The third and most ambitious option for creating a legal work-based pathway to highincome countries for refugees would be to establish new temporary labor migration programs (TMPs) specifically for displaced people who are currently in first countries of asylum in conflict regions. While the specific design of such programs might vary, the fundamental questions and challenges that they would raise are common to all countries.

To be politically and economically acceptable, the numbers admitted through a new TMP for refugees would almost certainly need to be capped or at least tightly regulated. The program might start with a relatively small pilot that could be scaled up based on early results. The eventual size of the program would largely depend on an assessment of the host country's demand for migrant labor.

From the host country's perspective, one of the most important selection criteria would be the skill level of migrants. The specific levels and types of skills targeted would be determined mainly by demand. But identifying and assessing the magnitude of labor and skills shortages in particular sectors and occupations, and deciding whether more migration is the best policy response, are typically highly contested issues. 
All TMPs, especially those designed to help fill low-skilled jobs, tend to result in segmentation of the labor market, which can have adverse consequences for domestic workers. Temporary migration programs frequently aim to help fill what are expected to be temporary shortages. However, they often lead to the permanent entrenchment of shortages, partly through discouraging hiring of domestic workers, and result in a structural demand for migrant labor.

While this may not always be undesirable from the host country's point of view, it can lead to the crowding out of at least some domestic workers and to the development of employer preferences for particular types of migrant workers. With this in mind, it may be most realistic to reserve the introduction of new TMPs for refugee-workers for sectors and occupations with relatively few competing domestic workers, and where migrants already constitute a relatively large share of the workforce.

For this reason, the Persian Gulf states would arguably find it easier to admit large numbers of refugee-workers than most other high-income countries. They are already large-scale importers of migrant workers, with segments of the labor market staffed mainly by migrants. This means that that there are many occupations where citizens are not competing for jobs. Given their highly segmented labor markets, the Gulf states could admit considerable numbers of refugee-workers without having to make fundamental changes to their existing labor immigration policies. The migration researcher Katy Long observed in the late 2000s that many refugees from countries like Afghanistan and Somalia had found de facto protection through becoming temporary workers in the Middle East.

To avoid undercutting prevailing employment conditions, refugee-workers should be given the same employment rights as domestic workers, or at least very similar ones. An important exception is the right to free choice of employment. This would need to be restricted to enable host countries to use migrants to address shortages in specific occupations or sectors.

To accommodate concerns about the net fiscal impacts of immigration, many high-income countries are likely to admit refugee-workers only if some of their social rights (such as access to cer- tain means-tested benefits) could be restricted, at least temporarily. In most such countries, restrictions on some welfare rights of new labor migrants are standard practice. Since refugee-workers are a particularly vulnerable group, however, such restrictions should be kept to a minimum to ensure that have good access to all the health, education, and other public services that they and their families need, especially for children.

Most temporary labor migration programs, especially those for lower-skilled workers, restrict migrants' rights to family reunion in one way or another. But it is difficult to see how admitting refugee-workers without granting them the right to bring at least some family members would provide the minimum degree of effective protection that most refugee families seek (though it would obviously be less of a concern for single refugees without families). In my view, at least some right to reunion (if only for core family members) would have to be an integral part of the policy. If this right does not already exist under an existing labor immigration program, a policy adjustment could be made for refugee-workers.

Depending on their economic models and circumstances, high-income countries may wish to impose slightly different selection criteria with regard to skills, occupations, and nationality, which could be facilitated by bilateral agreements. This raises the question of who will negotiate agreements and implement policies on behalf of refugee-workers. For obvious reasons, refugees' countries of origin cannot play this role. First countries of asylum in the region arguably are also unlikely to be effective advocates for refugees who wish to participate in labor immigration programs in high-income countries. Many will be under considerable pressure to negotiate such opportunities for their own citizens.

It may be possible for high-income countries to establish recruitment offices in countries of first asylum (as many European countries did when recruiting guest workers during the 1960s and 1970s). But it would likely be more effective and efficient to leave this job to international agencies such as the International Organization for Migration, UNHCR, and the International Labor Organization. In any case, to make temporary work programs for refugees viable, there is a need for a stable and reliable organization in refugees' cur- 
rent country of residence to negotiate and administer the program in the sending region.

\section{RETURN AND ASYLUM}

One of the most difficult challenges raised by admitting migrant workers on a temporary basis is how to ensure that those whose temporary work permits have expired and who have not been able to attain permanent residence status return to their home countries. While some TMPs have achieved high return rates, many others have been characterized by considerable degrees of illegal overstaying-one of the points frequently used by critics to argue against such programs. The question of whether and how to organize returns is even more difficult for TMPs that are specifically designed for refugee-workers.

Most importantly, to what country should refugee-workers be returned? The most realistic option would be to negotiate a return and readmission agreement with the country of residence-the first country of asylum-before refugees join the temporary labor migration program. Successfully negotiating such an agreement is likely to be a major but perhaps not insurmountable challenge. Most first countries of asylum are low- and lowermiddle-income countries themselves. It is likely that they will accept readmission agreements that involve the return of refugees only in exchange for greater opportunities for their own nationals to gain admission to higher-income countries as workers, students, or family migrants.

There are a number of other questions related to the modalities and enforcement of return. What if refugees whose temporary permits have expired refuse to return? Who will cover the costs? What status will refugees have after they return to the country of first asylum? What kind of employment, if any, would they find upon their return and what support would they need to find a job?

Another key question is whether refugees who have entered and reside in high-income countries under a labor immigration program should be allowed to change their status, for example to claim asylum. Most advocates of alternative pathways for refugees emphasize the importance of retaining their right to protection. But it is clear that the prospect of refugees using these alternative pathways to claim asylum would, in all likelihood, be a major disincentive for high-income countries to offer such pathways in the first place. They would surely want to avoid a situation in which refugees use a temporary labor immigration route to enter legally and then immediately (or after a brief interval) invoke their right to asylum to stay.

In theory, there are different ways in which refugees could be required to forfeit their right to claim asylum after admission to a high-income country under an alternative program. One option would be to deny that right to anyone who has entered via a labor immigration pathway. But this immediately raises the question of the right to be readmitted to the country of first asylum. Alternatively, high-income countries could stipulate that refugees entering under labor immigration programs cannot claim asylum (or otherwise switch categories) until their work permit or other permission to stay expires.

Both of these policies would likely violate existing international asylum laws and norms. But the latter policy of allowing migrants to claim asylum only at the end of their stay under a work program is arguably more realistic because it would come closer to complying with the principle of nonrefoulement (not returning refugees to a country where they may face serious danger and harm) and other international norms on protection.

\section{SHARING RESPONSIBILITY}

Any serious effort to help refugees around the world must include new policies that ease the pressures on the leading host countries, most of which are in low-income regions. High-income countries will need to support these policies with large increases in financial and other types of assistance as well as a range of measures to promote the welfare and labor market integration of refugees in countries of first asylum-especially those who have no realistic near-term prospect of returning safely to their home countries.

There are different ways of sharing responsibility among nation-states when it comes to the protection of refugees. The type and form of the contribution each country makes-whether hosting refugees, providing financial assistance, or adjusting economic and foreign policies to enable safe return-need not be the same for all countries.

Nevertheless, creating and maintaining legal pathways to protection in high-income countries is of fundamental importance to building a more equitable, effective, and sustainable system of global refugee protection. Rich countries should not be able to simply buy their way out of refugee protection at home. This sounds like a fairly basic and uncontroversial point, but in recent years it has been increasingly and openly challenged by 
more and more political parties and other influential voices in high-income countries.

Given the limited and currently declining number of resettlement options available to refugees in first countries of asylum, it is time to consider the desirability and feasibility of providing refugees with labor migration pathways and other alternative legal routes to high-income countries. But any new policy ideas and proposals for refugeeworkers should reflect the current realities of labor immigration policies in such countries. In light of the constraints and obstacles I have discussed, it is also important to recognize that labor migration is unlikely to become a major alternative pathway for large numbers of refugees.

However, there are opportunities for designing innovative policies that could be attractive both to refugees in low-income countries of first asylum and to employers and governments in some high- income countries. New policy designs will need to have an explicit dual purpose, combining the objectives of labor migration and humanitarian protection. This will inevitably involve at least some trade-offs between admission for refugee-workers and compliance with some of the protection principles enshrined in international asylum and refugee norms.

There are also considerable dangers of instrumentalizing refugees, in the sense of creating new policies that make the admission of refugees to high-income countries dependent, at least partially, on their perceived economic usefulness. For most refugees in first countries of asylum, the main legal pathway to protection in high-income countries should be resettlement. The key political challenge remains how to convince rich countries to radically increase the resettlement of refugees from overburdened lower-income countries. 